Journal of the Electrochemical Society, 1991, Volume 138, Issue 2, Pages 643-644.

ISSN: 0013-4651

DOI: $10.1149 / 1.2085652$

http://www.electrochem.org/

http://www.ecsdl.org/getpdf/servlet/GetPDFServlet?filetype=pdf\&id=JESOAN000138000002000643000001\&idtyp e=cvips\&prog $=$ normal

(C) The Electrochemical Society, Inc. 1991. All rights reserved. Except as provided under U.S. copyright law, this work may not be reproduced, resold, distributed, or modified without the express permission of The Electrochemical Society (ECS). The archival version of this work was published in Journal of the Electrochemical Society, 1991, Volume 138, Issue 2, Pages 643-644.

\title{
Repassivation Transients Measured with Thin Film Breaking Electrodes
}

\section{G. S. Frankel,* B. M. Rush, C. V. Jahnes, and C. E. Farrell}

IBM Research Division, T.J. Watson Research Center, Yorktown Heights, New York

A. J. Davenport* and H. S. Isaacs*

Brookhaven National Laboratory, Department of Applied Science, Upton, New York

*Electrochemical Society Active Member.

Scratched electrode experiments have been instrumental in developing our understanding of the passivation process (1-4). IR drops are minimized during scratching as only small areas of fresh metal are created. This is critical for maintaining potential control. In a recent report, however, Wei et al. have suggested that the surrounding passive film may affect the current measured in a scratched electrode experiment (5). They found that the maximum current measured after fracturing a sample in solution under potentiostatic control increased as the ratio of filmed area to fresh metal area increased. It was subsequently pointed out in a reply by Kelly and Newman (6) that the $1 \mathrm{~ms}$ sampling period used by Wei et al. caused them to miss a considerable portion of the current decay which occurs at shorter times and that the large fracture surface areas likely resulted in substantial IR drops. Kelly and Newman also reported results using a scratched electrode which indicated that the maximum measured current was independent of the filmed to fresh metal area ratio.

While it is possible to collect data from a scratched electrode at a high rate, it is inherently impossible to observe the very initial stages of passivation with this technique due to the time needed for scratching which is typically in the range of $0.1-1 \mathrm{~ms}$. As the end of the scratch is just being created, the beginning has experienced significant repassivation. In this communication, we report a technique to expose extremely small areas of fresh metal very quickly and reproducibly by breaking a thin film electrode deposited on glass (7). In this fashion, the earliest stages of repassivation may be monitored and the effects of the neighboring passive film may be elucidated.

\section{EXPERIMENTAL}

The electrodes used in this study were nominally $2 \mathrm{~mm}$ wide $\times 1 \mu \mathrm{m}$ thick strips of $\mathrm{Al}$ evaporated through a mask onto glass slides. The glass was notched with a diamond saw on either side of the strip at a given location to facilitate breaking. The electrode was then cantilevered into a plexiglass cell through a slot in the side and secured at the notches with a plexiglass clamp. A notch was also cut into the clamp so that $0.02 \mathrm{~cm}^{2}$ of the strip remained directly exposed to the solution after the sample was broken. Breaking was achieved by a spring- 
loaded plexiglass guillotine. A PAR 173 potentiostat was used, and the current output was monitored in parallel by a Nicolet 4094A/4562 oscilloscope and an HP 3458A multimeter with sampling times of 0.5 and $10 \mu$ s and resolutions of 12 and 16 bits, respectively. The solution was $0.6 \mathrm{M} \mathrm{K}_{2} \mathrm{SO}_{4}$. A mercurous sulfate reference electrode (MSE) and a gold counter electrode were inserted into the cell at a distance from the sample. Prior to breaking, some of the samples were first coated with approximately $1000 \AA$ of sputtered $\mathrm{SiO}_{2}$.

\section{RESULTS AND DISCUSSION}

Figure 1 shows two transients measured by breaking samples at a potential of $0 \mathrm{mV}$ MSE. The initial current increase is rapid, attaining a maximum after a few $\mu$ s. This is more than two orders of magnitude faster than by scratching. Assuming the area of the freshly exposed metal to be the cross section of approximately $2 \times 10^{-5} \mathrm{~cm}^{2}$, the peak current of $8 \mathrm{~mA}$ corresponds to a current density of $400 \mathrm{~A} / \mathrm{cm}^{2}$. This is much higher than that typically measured in a scratched electrode experiment.

The transients shown in Fig. 1, which are representative of many experiments, also indicate that a thick oxide coating on the electrode has a significant effect. The measured peak currents for the coated samples (e.g. curve a) were consistently higher than for the uncoated samples (e.g. curve b), typically by about a factor of 2 to 3 . The currents from the coated samples also rose and decayed faster, intersecting the current of uncoated samples after a few $\mu$ s.

Upon breaking an uncoated sample, there is rapid discharging of the surface capacitance of the passive film near the break. This supplies current to the fresh area within the first few $\mu$ s. As this current is not supplied by the potentiostat, the measured current is erroneously low. The passive film is subsequently recharged by current from the potentiostat so at longer times the measured current is erroneously high by a small amount. In contrast, the $\mathrm{SiO}_{2}$-coated sample has a much lower capacitance which supplies less current. The measured current increases faster, achieves a higher peak value, and decays faster, behavior which is more representative of the actual repassivation characteristics of bare metal. The capacitance of the passive film acts much like a filter by damping the response of the potentiostat. In a real system, a repassivation event is inextricably linked to interactions with the surrounding passive surface area $(8,9)$.

The transients converted to current density are plotted on a log scale in Figure 2. While the differences are significant and reproducible, they would be missed in a scratched electrode experiment or if the sampling rate were not sufficiently fast. Preliminary experiments on iron have shown this effect to be much more pronounced. This is consistent with the higher capacitance of the passive iron surface compared to that of passive aluminum. The current density peak of the uncoated Fe is about 5 times lower and occurs about $30 \mu$ s later than for the case of $\mathrm{SiO}_{2}$-coated $\mathrm{Fe}$. A detailed description of all the findings is forthcoming (10).

\section{CONCLUSIONS}

A technique is described for studying the early stages of passivation by breaking thin films deposited onto glass. In this fashion, small fresh metal areas are very quickly and reproducibly created. For Al, peak current densities on the order of hundreds of $\mathrm{A} / \mathrm{cm}^{2}$ were observed within a few $\mu$ s after breaking. Coating of the $\mathrm{Al}$ with sputtered $\mathrm{SiO}_{2}$ resulted in higher currents, as well as faster increases and decays indicating that the passive film next to a repassivating area interacts with the repassivation process. 


\section{ACKNOWLEDGEMENTS}

A.J.D. and H.S.I, were supported by the U.S. Department of Energy, Division of Materials Sciences, Office of Basic Energy Science under Contract No. DE-AC02-76CH00016.

\section{REFERENCES}

1. G. T. Burstein and D. H. Davies, This Journal, 128, 33 (1980).

2. H. J. Pearson, G. T. Burstein, and R. C. Newman, ibid., 128, 2297 (1981).

3. G. T. Burstein and P. I. Marshall, Corr. Sci., 23, 125 (1983).

4. G. T. Burstein and A. J. Davenport, This Journal, 136, 936 (1989).

5. R. P. Wei, M. Gao, and P. Y. Xu, ibid., 136, 1835 (1989).

6. R. G. Kelly and R. C. Newman, ibid., 137, 357 (1990).

7. A. J. Davenport and H. S. Isaacs, Proc. of Transient Techn. in Corr, Sci. and Eng., The Electrochemical Society, 89-1 (1989).

8. H. S. Isaacs and A. J. Davenport, This Journal, 137, 2196 (1990).

9. R. Oltra, G. M. Indrianjafy, J. C. Colson, and M. Keddam, Proc. 11th Int. Corr. Cong., AIM, Florence, Italy (1990).

10. G. S. Frankel, B. M. Rush, C. V. Jahnes, C. E. Farrell, A. J. Davenport, and H. S. Isaacs, in preparation.

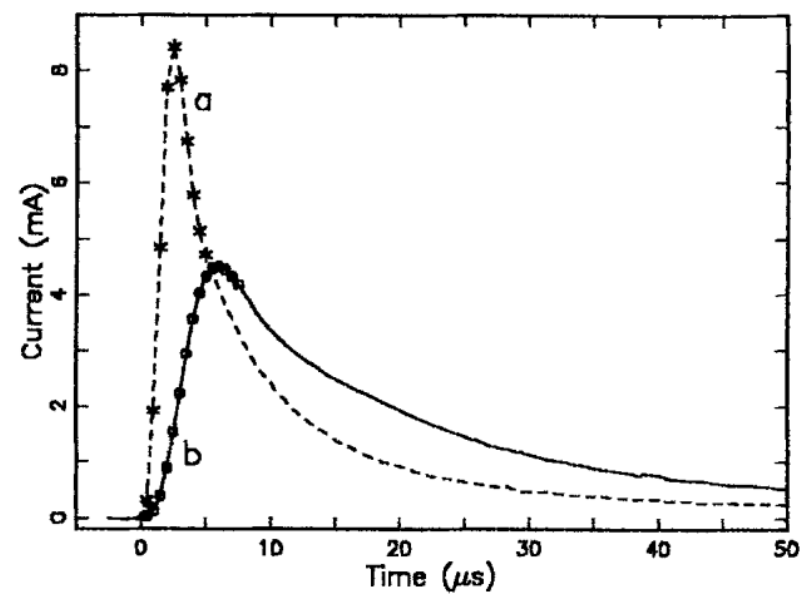

Figure 1. Current transients for $\mathrm{Al}$ breaking electrodes at $0 \mathrm{mV}$ MSE in $0.6 \mathrm{M} \mathrm{K}_{2} \mathrm{SO}_{4}$. a) $\mathrm{SiO}_{2}$-coated sample b) uncoated sample. A few data points at the initial portions of the transients are plotted to show the resolution of the technique. 


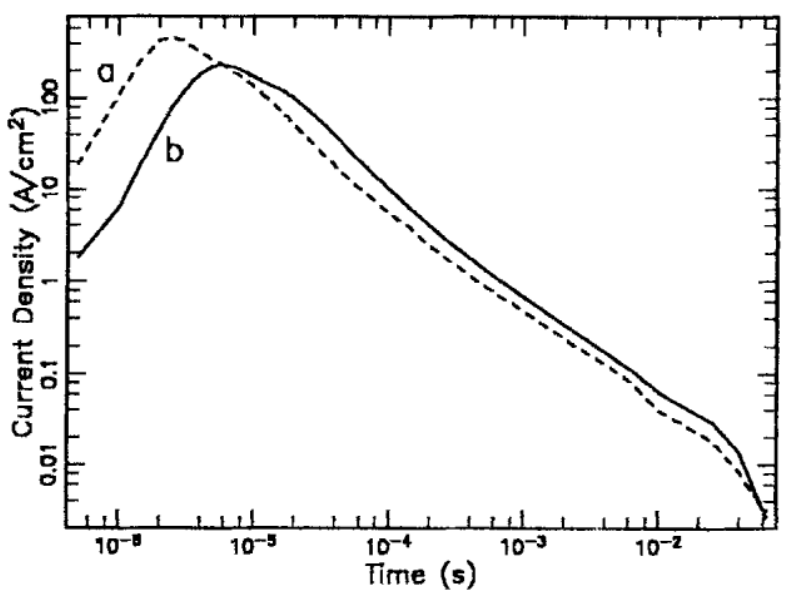

Figure 2. Transients from Fig. 1 plotted as current density and on $\log$ scale, a) $\mathrm{SiO}_{2}$-coatcd sample b) uncoated sample.

IBM Research Division T. J. Watson Research Center assisted in meeting the publication costs of this article. 